\title{
The genome-wide supported CACNA1C gene polymorphisms and the risk of schizophrenia: an updated meta-analysis
}

\author{
Yong-ping Liu, Xue Wu, Xi Xia, Jun Yao* and Bao-jie Wang ${ }^{*}$ (D)
}

\begin{abstract}
Background: The CACNA1C gene was defined as a risk gene for schizophrenia in a large genome-wide association study of European ancestry performed by the Psychiatric Genomics Consortium. Previous meta-analyses focused on the association between the CACNA1C gene rs1006737 and schizophrenia. The present study focused on whether there was an ancestral difference in the effect of the CACNA1C gene rs1006737 on schizophrenia. rs2007044 and rs4765905 were analyzed for their effect on the risk of schizophrenia.
\end{abstract}

Methods: Pooled, subgroup, sensitivity, and publication bias analysis were conducted.

Results: A total of 18 studies met the inclusion criteria, including fourteen rs 1006737 studies (15,213 cases, 19,412 controls), three rs2007044 studies (6007 cases, 6518 controls), and two rs4765905 studies (2435 cases, 2639 controls). An allele model study also related rs2007044 and rs4765905 to schizophrenia. The overall meta-analysis for rs1006737, which included the allele contrast, dominant, recessive, codominance, and complete overdominance models, showed significant differences between rs1006737 and schizophrenia. However, the ancestral-based subgroup analysis for rs 1006737 found that the genotypes GG and GG + GA were only protective factors for schizophrenia in Europeans. In contrast, the rs1006737 GA genotype only reduced the risk of schizophrenia in Asians.

Conclusions: Rs 1006737, rs2007044, and rs4765905 of the CACNA1C gene were associated with susceptibility to schizophrenia. However, the influence model for rs1006737 on schizophrenia in Asians and Europeans demonstrated both similarities and differences between the two ancestors.

Keywords: Meta-analysis, CACNA1C, rs1006737, rs2007044, rs4765905, Schizophrenia

\section{Background}

Schizophrenia is a chronic, disabling brain disease characterized by delusions, hallucinations, and formal thought disorders in addition to a decline in socio-occupational functioning [1]. Studies with twins [2] and adoptive families [3] have shown that genetic factors are an important cause of schizophrenia. The L-type voltage-gated calcium channels play a unique role in behavioral extinction [4], inhibitory learning, and the maturation of adult cognitive

\footnotetext{
* Correspondence: yaojun198717@163.com; wangbj77@163.com School of Forensic Medicine, China Medical University, No.77 Puhe Road, Shenbei New District, Shenyang 110122, China
}

function [5]. The two principal pore-forming subunits of these channels expressed in neurons are the $\alpha 1 \mathrm{C}$ and $\alpha 1 \mathrm{D}$ subtypes [6]. The $\alpha 1 \mathrm{C}$ subtype is encoded by the CACNA1C gene, which is considered a risk factor for schizophrenia based on a large genome-wide association study (GWAS) of European ancestry performed by the Psychiatric Genomics Consortium (PGC) [7]. A growing body of research supports a key role for $C A C N$ $A 1 C$ in schizophrenia in Europeans. Ivorra et al. [8] found that the rs 1006737 polymorphism of the $C A C N$ $A 1 C$ gene is strongly associated with schizophrenia and bipolar disorder in a Spanish sample. Wolf et al. [9]

(c) The Author(s). 2020 Open Access This article is licensed under a Creative Commons Attribution 4.0 International License, which permits use, sharing, adaptation, distribution and reproduction in any medium or format, as long as you give appropriate credit to the original author(s) and the source, provide a link to the Creative Commons licence, and indicate if changes were made. The images or other third party material in this article are included in the article's Creative Commons licence, unless indicated otherwise in a credit line to the material. If material is not included in the article's Creative Commons licence and your intended use is not permitted by statutory regulation or exceeds the permitted use, you will need to obtain permission directly from the copyright holder. To view a copy of this licence, visit http://creativecommons.org/licenses/by/4.0/ The Creative Commons Public Domain Dedication waiver (http://creativecommons.org/publicdomain/zero/1.0/) applies to the data made available in this article, unless otherwise stated in a credit line to the data. 
suggested that the CACNA1C genotype may explain inter-individual differences in the amygdala volume among patients with schizophrenia in the German sample. The amygdala is not only involved in associative learning but also regulates additional cognitive processes, such as memory and attention [10]. Fatima et al. [11] detected a significant difference in the genotype and allele frequencies for the rs4765905 polymorphism between patients and controls, confirming the hypothesis that the $C A C N$ $A 1 C$ gene was associated with schizophrenia in the Pakistani sample. Rs1006737 and rs4765905 are located in intron 3 of $C A C N A 1 C$ gene. And previous study [12] have shown that disease-related SNPs in the CACNA1C gene (including rs1006737 and rs4765905) were proven to be expression quantitative trait loci (eQTLs), which are located in a region interacting with the promoter of $C A C N A 1 C$, and may regulate the expression of $C A C N$ $A 1 C$ in the brain.

Based on these findings, we were curious to see if the CACNA1C gene had the same effect on schizophrenia in Asians as it did in the Europeans. The meta-analysis of Zheng et al. [13] and Jiang et al. [14] showed that there was no heterogeneity between the CACNA1C rs1006737 polymorphism in East Asians and Europeans. He et al. [15] also showed that rs1006737 was associated with both schizophrenia and major depressive disorder in the Han Chinese sample. Additional rs1006737 meta-analysis showed an association between this CACNA1C polymorphism and schizophrenia in both the Europeans and Asians when the samples were stratified by ethnicity [16]. However, in a follow-up to the top European GWAS hits, The genotyping performed by Takahashi et al. [17] implicated loci in additional schizophrenia family samples from China and Japan and found no association between 12 polymorphisms (e.g., rs4765905 in the CACNA1C gene) and schizophrenia. Consistent with this finding, Hori et al. [18] found no significant difference in the genotype or allele frequency of the CACNA1C rs1006737 polymorphism between schizophrenia patients and controls in a Japanese sample.

In summary, there is no consensus on whether $C A C N$ $A 1 C$ is associated with schizophrenia or if there are differences in susceptibility to schizophrenia between Asians and Europeans. Therefore, we performed an updated comprehensive meta-analysis on the relationship between CACNA1C gene polymorphisms and schizophrenia, which included case-control studies.

\section{Methods}

\section{Literature search strategy}

To identify eligible studies, we searched two electronic databases, PubMed and China's National Knowledge Infrastructure [CNKI]. English studies were obtained by PubMed (2011-Present) database, and Chinese studies were obtained by CNKI (2013-Present) database. Only completed peer-review studies have the potential to be included in the present meta-analysis. The last search update was in November 2019. Rs1006737, rs2007044, rs4765905, CACNA1C, and schizophrenia were selected as search keywords.

The inclusion criteria for the present study were: a. including patients with schizophrenia; b. containing detailed genotypes and allele frequencies; c. including healthy control population; $\mathrm{d}$. stating $C A C N A 1 C$ may be a potential gene of schizophrenia; e. the type of studies were case-control studies. The current exclusion criteria for meta-analysis were: $a$. no schizophrenic patients; $b$. no detailed genotype frequency data; c. no controls; $d$. abstracts, meta-analysis or reviews; e. not case-control studies; f. including repeated sample; g. containing 2014 PGC GWAS data [19].

\section{Data extraction}

Two independent authors conduct data extraction according to the inclusion and exclusion criteria. If there was inconsistency between the two authors, they will hold discussions until an agreement was reached. Table 1 summarizes the first author's last name, publication year, region, ancestry, source of control, mean age of control group, gender index, number of case group and control group, and the number of genotypes in case and control group.

\section{Sensitivity analysis and publication bias}

Sensitivity analysis was used to evaluate whether the combined results were stable and reliable. Funnel plots (the $\mathrm{x}$-axis was the logarithm of OR, and the $\mathrm{y}$-axis was the standard error of the logarithm of the OR) were used to determine whether the included studies had publication bias. Egger's test [32] was used to assess the level of publication bias. $P$-value greater than 0.05 indicates a publication bias.

\section{Statistical analysis}

We evaluated the Hardy-Weinberg equilibrium (HWE) in the control group of each study using Pearson's chi-square test. The odds ratios (ORs) and 95\% confidence intervals (CIs) were used to evaluate the correlation between polymorphisms rs1006737, rs4765905, rs2007044 and schizophrenia risk. The Cochran's Q-test [33] and $\mathrm{I}^{2}$ statistics [34] were selected to check the heterogeneity among studies. Cochran's Q-test is qualitative. If a $P$-value was greater than 0.1, it means a lack of heterogeneity, and the fixed effect model (Mantel-Haenszel) was selected. Conversely, a $p$-value was less than 0.1 , indicating the existence of heterogeneity. The random effect model ( $\mathrm{M}-\mathrm{H}$ heterogeneity) was selected [35]. $\mathrm{I}^{2}$ is quantitative statistics, which refers to the ratio of the variation between studies to the 
Table 1 The main characteristics of the studies included in the meta-analysis

\begin{tabular}{|c|c|c|c|c|c|c|c|c|}
\hline Author & Year & Country & Ancestor & $\begin{array}{l}\text { Source of } \\
\text { control group }\end{array}$ & $\begin{array}{l}\text { Mean age of } \\
\text { control group }\end{array}$ & $\begin{array}{l}\text { Gender index } \\
\text { (case) }\end{array}$ & $\begin{array}{l}\text { Gender index } \\
\text { (control) }\end{array}$ & Case/Control \\
\hline \multicolumn{9}{|l|}{ Rs1006737 } \\
\hline Fatima [11] & 2017 & Pakistani & Caucasian & Population based & 44 & 0.33 & 0.71 & $508 / 300$ \\
\hline Lubeiro [20] & 2018 & Spain & Caucasian & Population based & 29.52 & 0.72 & 0.98 & $50 / 101$ \\
\hline Mallas [21] & 2016 & Mixed & Mixed & Population based & 35.79 & 0.26 & 0.85 & $63 / 124$ \\
\hline Porcelli [22] & 2015 & Korean & Asian & Hospital based & 45.36 & 0.73 & 1.22 & $176 / 326$ \\
\hline Ivorra [8] & 2014 & Spain & Caucasian & Mixed & 43.61 & 0.79 & 0.75 & $3063 / 2847$ \\
\hline $\mathrm{He}[15]$ & 2013 & China & Asian & Population based & 30.6 & 0.53 & 0.86 & $1235 / 1235$ \\
\hline Guan [23] & 2013 & China & Asian & Population based & 34.2 & 0.87 & 0.83 & $1430 / 1570$ \\
\hline Galaktionova [24] & 2013 & Russia & Caucasian & Population based & 36 & 2.24 & 0.90 & 188/192 \\
\hline Zheng [13] & 2013 & China & Asian & Population based & 32.4 & 1.05 & 1.04 & $5893 / 6319$ \\
\hline Hori [18] & 2012 & Japan & Asian & Population based & 46 & 0.82 & 1.93 & $552 / 1132$ \\
\hline Zhang [25] & 2011 & China & Asian & Population based & 22.3 & 0.49 & 0.60 & $318 / 401$ \\
\hline Nyegaard [26] & 2010 & Denmark & Caucasian & Population based & - & - & - & $976 / 1489$ \\
\hline Bigos [27] & 2010 & & Caucasian & Population based & 33.09 & 0.230 & 1.16 & $282 / 440$ \\
\hline Green [28] & 2009 & UK & Caucasian & Population based & - & 0.47 & 1.04 & 479/2936 \\
\hline \multicolumn{9}{|l|}{ Rs2007044 } \\
\hline Bustillo [29] & 2017 & United States & Caucasian & Population based & 36 & 0.26 & 0.37 & $53 / 129$ \\
\hline Zhang [30] & 2018 & China & Asian & Hospital based & 27.14 & 0.15 & 0.28 & $53 / 129$ \\
\hline \multicolumn{9}{|l|}{ Rs4765905 } \\
\hline Sudesh [31] & 2018 & India & Indian & Population based & 38.73 & 1.01 & 0.483 & $1005 / 1069$ \\
\hline
\end{tabular}

Notes: Gender index = female/male; Guan's study included the main characteristics of both rs1006737 and rs4765905; Zheng's study included the main characteristics of both rs1006737 and rs2007044

total variation. It was divided into three groups according to heterogeneity level: low (less than $25 \%$ ), moderate (25 to $75 \%$ ), and high (greater than 75\%). The "a" was marked as the risk allele. We use allelic: a vs. A, dominant: Aa + AA vs. AA, recessive: aa vs. AA, and codominant: aa vs. AA and Aa vs. AA, and complete overdominance: $\mathrm{AA}+$ aa vs. Aa models to calculate the pooled ORs. Besides, a subgroup analysis based on ancestry was conducted.

Meta-regression analysis was performed to assess the impact of different variables (mean age of control group and sex indexes) on the analysis. Statistical calculations were performed using Stata version 12.0 (StataCorp LP, College Station, TX, USA) software. $P$-value less than 0.05 indicates statistical difference (two tails).

\section{Results}

We investigated 67 related articles from PubMed and CNKI electronic databases. Studies that did not conform to the inclusion criteria were excluded, and 18 studies were available for meta-analysis (Fig.1). Specifically, these 18 studies included 14 rs1006737 studies $(15,213$ cases and 19,412 controls), three rs2007044 studies (6007 cases and 6518 controls), and two rs4765905 studies (2435 cases and 2639 controls). The allelic and genotype distributions of all included studies were summarized in Table 2.

\section{CACNA1C Rs 1006737 polymorphism}

ORs were estimated in allelic (A vs. G), dominant (GA + AA vs. GG), recessive (AA vs. GG), codominance (AA vs. GG and GA vs. GG), and complete overdominance (GG + AA vs. GA) models (A was the risk allele). All models except for the codominance model (GA vs. GG) were performed using the fixed effects model $(\mathrm{M}-\mathrm{H})$ due to the low heterogeneity. In contrast, the codominance model (GA vs. GG) was performed using the random effects model $(\mathrm{M}-\mathrm{H})$ due to its high heterogeneity $\left(\mathrm{I}^{2}=99 \%\right)$.

The overall meta-analysis (Table 3 ) showed that rs1006737 was significantly associated with schizophrenia risk in the following models: allele model (A vs. G: $P=0.000, \mathrm{OR}=1.151,95 \% \mathrm{CI}=1.100-1.204, \mathrm{I}^{2}=0.0 \%, P$ heterogeneity $=0.867)$; dominant model $(\mathrm{GA}+\mathrm{AA}$ vs. GG: $P=0.000, \mathrm{OR}=1.169,95 \% \mathrm{CI}=1.107-1.234, \mathrm{I}^{2}=$ $0.0 \%, P$ heterogeneity $=0.786$ ); recessive model (AA vs. GG + GA: $P=0.001, \mathrm{OR}=1.215,95 \% \mathrm{CI}=1.085-1.360$, $\mathrm{I}^{2}=0.0 \%, P$ heterogeneity $\left.=0.999\right)$; codominance models (AA vs. GG: $P=0.000$, $\mathrm{OR}=1.296,95 \% \mathrm{CI}=1.151$ $1.459, \mathrm{I}^{2}=0.0 \%, P$ heterogeneity $=0.993$ ); codominance model (GA vs. GG: $P=0.000, \mathrm{OR}=0.064,95 \% \mathrm{CI}=$ 


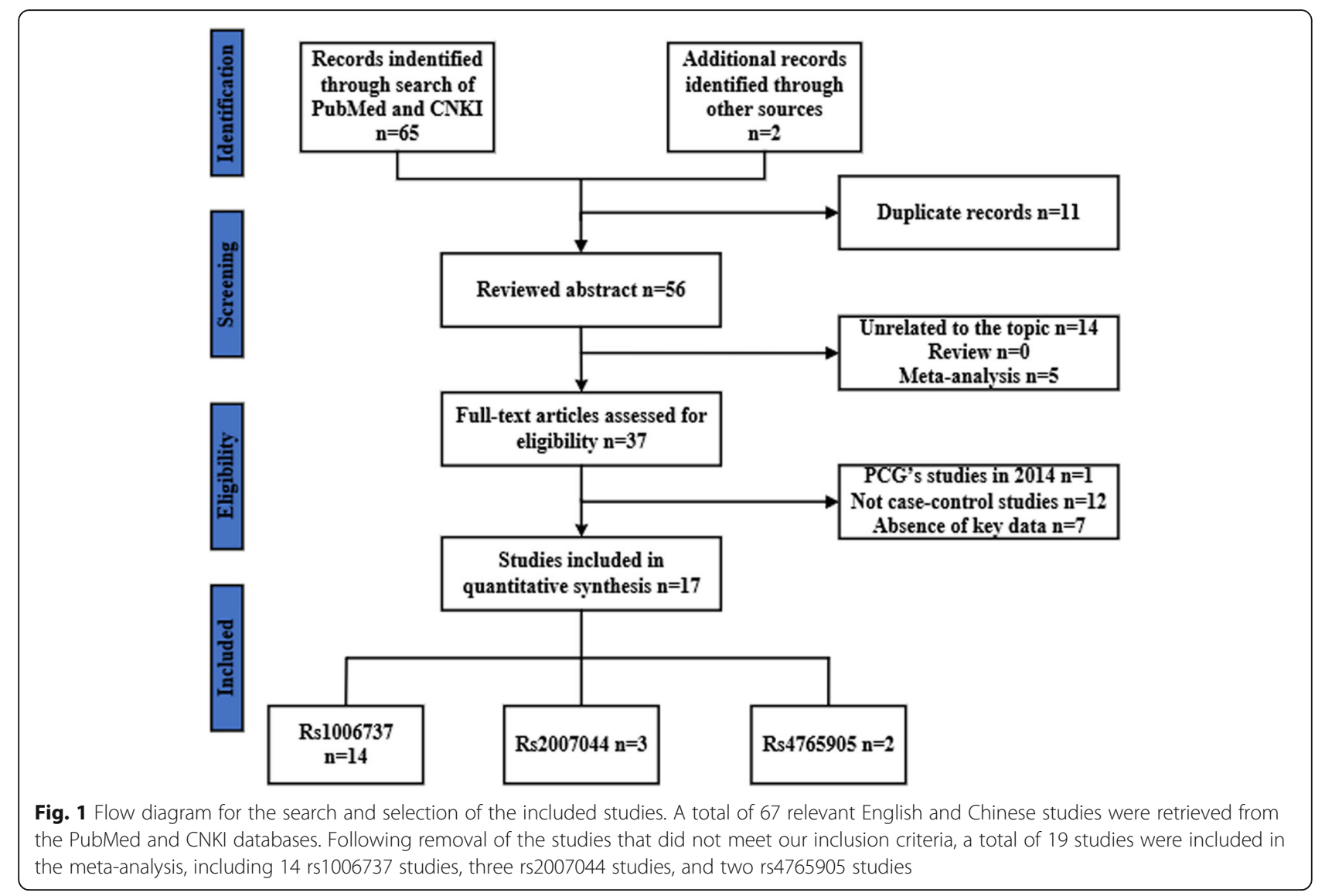

0.024-0.169, $\quad \mathrm{I}^{2}=99 \%, \quad P$ heterogeneity $\left.=0.000\right)$, and complete overdominance model (GG + AA vs. GA: $P=$ $0.000, \mathrm{OR}=0.897,95 \% \mathrm{CI}=0.849-0.948, \mathrm{I}^{2}=26.1 \%, P$ heterogeneity $=0.173$ ).

Subsequently, subgroup analysis based on ancestor was performed for rs1006737. For the Caucasians, there were seven studies that included a total of 5546 patients with schizophrenia and 8305 controls. Rs1006737 was associated with schizophrenia using all but one genetic model (A vs. G, $P=0.000, \mathrm{OR}=1.121,95 \% \mathrm{CI}=1.060-1.186 ; \mathrm{GA}+\mathrm{AA}$ vs. GG, $P=0.001$, $\mathrm{OR}=1.127,95 \% \mathrm{CI}=1.047-1.213$; $\mathrm{AA}$ vs. $\mathrm{GG}+\mathrm{GA}, P=0.003$, $\mathrm{OR}=1.203,95 \% \mathrm{CI}=1.067-1.357$; AA vs. GG, $P=0.000, \mathrm{OR}=1.284,95 \% \mathrm{CI}=1.131-1.456$; GA vs. GG, $P=0.001, \mathrm{OR}=0.279,95 \% \mathrm{CI}=0.132-0.587)$. The complete overdominance model (GG + AA vs. GA) resulted in an $\mathrm{OR}=0.959,95 \% \mathrm{CI}=0.891-1.033$, and $P=0.272$.

The subgroup analysis also included six studies involving Asians with a total of 9604 patients with schizophrenia and 10,983 controls. Rs1006737 was associated with schizophrenia using the following models: allele contrast model (A vs. G: $P=0.000, \mathrm{OR}=1.206,95 \% \mathrm{CI}=1.117-$ 1.303); dominant model (GA + AA vs. GG: $P=0.000$, $\mathrm{OR}=1.219,95 \% \mathrm{CI}=1.123-1.323)$; codominance model
(GA vs. GG; OR $=0.008,95 \% \mathrm{CI}=0.004-0.017, \quad P=$ 0.000); complete overdominance model (GG + AA vs. GA: $P=0.000, \mathrm{OR}=0.827,95 \% \mathrm{CI}=0.761-0.899)$. There was no association observed using the recessive (AA vs. GG + GA: $P=0.125$, OR $=1.336,95 \% \mathrm{CI}=0.922-1.936)$ or codominance model (AA vs. GG: $P=0.086$, OR = 1.384, 95\% CI $=0.955-2.006$ ) models (Table 4). Neither the mean age of the control group (slope $=0.995,95 \%$ $\mathrm{CI}=0.985-1.005, P=0.265$ ) nor the sex indexes (case group, $\quad$ slope $=0.943, \quad 95 \% \quad \mathrm{CI}=0.797-1.115, \quad P=$ 0.455 ; control group, slope $=1.059,95 \% \mathrm{CI}=0.829-$ 1.352, $P=0.616$ ) had any significant impact on the results.

\section{Rs2007044 and rs4765905 polymorphisms of CACNA1C}

Allele $\mathrm{G}$ of rs2007044 and allele C of rs4765905 were defined as risk alleles. Because relatively few studies related to rs2007044 and rs4765905 were included in the metaanalysis, only the allele model for these two polymorphisms was analyzed. Significant differences between the patients and controls were observed for both rs2007044 (G vs. A: $P=0.006, \mathrm{OR}=1.080,95 \% \mathrm{CI}=1.023-1.139$ ) and rs4765905 ( $\mathrm{C}$ vs. G: $P=0.000, \mathrm{OR}=1.225,95 \% \mathrm{CI}=$ 1.100-1.364). The main results are presented in Table 3. 
Table 2 The distributions of the allele frequency and genotype in the included studies

\begin{tabular}{|c|c|c|c|c|c|c|c|c|c|c|c|c|}
\hline \multirow{3}{*}{$\begin{array}{l}\text { Author } \\
\text { SS }\end{array}$} & \multirow[t]{3}{*}{ Year } & \multicolumn{6}{|c|}{ Genotype distribution } & \multicolumn{2}{|c|}{$\underline{P H W E}$} & \multicolumn{3}{|c|}{ Allele frequency } \\
\hline & & \multicolumn{3}{|c|}{ Cases, $\mathrm{n}$} & \multicolumn{3}{|c|}{ Controls, n } & & \multicolumn{2}{|l|}{ Cases (\%) } & \multicolumn{2}{|l|}{ Control (\%) } \\
\hline & & $\overline{A A}$ & $\mathrm{Aa}$ & aa & $\overline{A A}$ & $\mathrm{Aa}$ & aа & & $\mathrm{A}$ & a & $\bar{A}$ & a \\
\hline \multicolumn{13}{|l|}{ Rs1006737 } \\
\hline Lubeiro & 2018 & 25 & 23 & 2 & 58 & 38 & 5 & 0.70 & $73(73.0)$ & $27(27.0)$ & $154(76.2)$ & $48(23.8)$ \\
\hline Fatima & 2017 & 393 & 84 & 17 & 235 & 54 & 9 & 0.01 & $870(88.1)$ & $118(11.9)$ & $524(88.0)$ & $72(12.0)$ \\
\hline Ivorra & 2014 & 1417 & 1271 & 293 & 1420 & 1124 & 240 & 0.41 & $4105(68.9)$ & $1857(31.1)$ & 3964 (71.2) & $1604(28.8)$ \\
\hline Galaktionova & 2013 & 78 & 85 & 23 & 80 & 90 & 22 & 0.66 & $241(64.8)$ & $131(35.2)$ & $250(65.1)$ & $134(34.9)$ \\
\hline Nyegaard & 2010 & 402 & 444 & 130 & 656 & 675 & 158 & 0.42 & $1248(63.9)$ & $704(36.1)$ & $1987(66.7)$ & 991 (33.3) \\
\hline Bigos & 2010 & 120 & 115 & 47 & 191 & 205 & 44 & 0.31 & $355(62.9)$ & $209(37.1)$ & $587(66.7)$ & $293(33.3)$ \\
\hline Green & 2009 & 205 & 208 & 66 & 1367 & 1233 & 336 & 0.02 & $618(64.5)$ & $340(35.5)$ & 3967 (67.6) & 1095 (32.4) \\
\hline Mallas & 2016 & 23 & 30 & 10 & 56 & 51 & 17 & 0.33 & $76(60.3)$ & $50(39.7)$ & $163(65.7)$ & 85 (34.3) \\
\hline Porcelli & 2015 & 153 & 23 & 0 & 301 & 23 & 2 & 0.11 & 329 (93.5) & $23(6.5)$ & 625 (95.9) & $27(4.1)$ \\
\hline $\mathrm{He}$ & 2013 & 996 & 220 & 14 & 1053 & 166 & 9 & 0.39 & $2212(89.9)$ & $248(10.1)$ & $2272(92.5)$ & $184(7.5)$ \\
\hline Guan & 2013 & 1061 & 343 & 26 & 1223 & 327 & 20 & 0.72 & 2465 (86.2) & 395 (13.8) & 2773 (88.3) & 367 (11.7) \\
\hline Zheng & 2013 & 5239 & 635 & 19 & 5706 & 597 & 16 & 0.93 & $11,113(94.3)$ & $673(5.7)$ & $12,009(95.0)$ & $629(5.0)$ \\
\hline Hori & 2012 & 480 & 70 & 2 & 1002 & 127 & 3 & 0.63 & 1030 (93.3) & $74(6.7)$ & 2131 (94.1) & $133(5.9)$ \\
\hline Zhang & 2011 & 280 & 37 & 1 & 357 & 42 & 2 & 0.53 & 597 (93.9) & $39(6.1)$ & $756(94.3)$ & $46(5.7)$ \\
\hline \multicolumn{13}{|l|}{ Rs2007044 } \\
\hline Zhang & 2018 & 24 & 25 & 4 & 58 & 57 & 14 & 1.00 & 73 (68.9) & 33 (31.1) & $173(67.1)$ & 85 (32.9) \\
\hline Bustillo & 2017 & 26 & 23 & 9 & 35 & 21 & 11 & 0.02 & 75 (64.7) & $41(35.3)$ & $91(67.9)$ & $43(32.1)$ \\
\hline Zheng & 2014 & 2797 & 2540 & 559 & 3166 & 2597 & 559 & 0.42 & 8134 (77.5) & $3658(22.5)$ & 8929 (70.7) & 3715 (29.3) \\
\hline \multicolumn{13}{|l|}{ Rs4765905 } \\
\hline Sudesh & 2018 & 579 & 307 & 51 & 668 & 286 & 38 & 0.29 & $1465(78.2)$ & 409 (21.8) & $1622(81.8)$ & $362(18.2)$ \\
\hline Guan & 2013 & 1307 & 360 & 33 & 1195 & 352 & 24 & 0.74 & $2434(71.6)$ & $426(28.4)$ & $2741(87.2)$ & 399 (12.8) \\
\hline
\end{tabular}

Notes: $P_{\text {HWE }}, P$-value of the Hardy-Weinberg equilibrium; A, wild-type allele; a, mutant allele

Table 3 The main results of the overall meta-analysis of CACNA1C polymorphisms

\begin{tabular}{|c|c|c|c|c|c|c|}
\hline Genetic model & OR & $95 \% \mathrm{Cl}$ & $\boldsymbol{P}$-value & $I^{2}(\%)$ & $P_{\mathrm{h}}$ & Combination method \\
\hline \multicolumn{7}{|l|}{ Rs1006737 } \\
\hline Allele contrast & 1.151 & $1.100-1.204$ & 0.000 & 0.0 & 0.867 & Fixed effects model \\
\hline Dominant & 1.169 & $1.107-1.234$ & 0.000 & 0.0 & 0.786 & Fixed effects model \\
\hline Recessive & 1.215 & $1.085-1.360$ & 0.001 & 0.0 & 0.999 & Fixed effects model \\
\hline Codominance AA vs. GG & 1.296 & $1.151-1.459$ & 0.000 & 0.0 & 0.993 & Fixed effects model \\
\hline Codominance GA vs. GG & 0.064 & $0.024-0.169$ & 0.000 & 99.0 & 0.000 & Random effects model \\
\hline Complete overdominance & 0.897 & $0.849-0.948$ & 0.000 & 26.1 & 0.173 & Fixed effects model \\
\hline \multicolumn{7}{|l|}{ Rs2007044 } \\
\hline Allele contrast & 1.080 & $1.023-1.139$ & 0.006 & 0.0 & 0.785 & Fixed effects model \\
\hline \multicolumn{7}{|l|}{ Rs4765905 } \\
\hline Allele contrast & 1.225 & $1.100-1.364$ & 0.000 & 0.0 & 0.719 & Fixed effects model \\
\hline
\end{tabular}


Table 4 Subgroup analysis of the association between rs1006737 and the risk of schizophrenia

\begin{tabular}{|c|c|c|c|c|c|}
\hline \multirow[t]{2}{*}{ Ancestor } & \multicolumn{3}{|c|}{ Summary of pooled ORs } & \multicolumn{2}{|c|}{ Heterogeneity test } \\
\hline & $\overline{\mathrm{OR}}$ & $95 \% \mathrm{Cl}$ & $\boldsymbol{P}$-value & $\overline{1^{2}(\%)}$ & $P_{\mathrm{h}}$ \\
\hline \multicolumn{6}{|l|}{ Asian } \\
\hline Allele contrast & 1.206 & $1.117-1.303$ & 0.000 & 0.0 & 0.583 \\
\hline Dominant & 1.219 & $1.123-1.323$ & 0.000 & 0.0 & 0.484 \\
\hline Recessive & 1.336 & $0.922-1.936$ & 0.125 & 0.0 & 0.939 \\
\hline Codominance AA vs. GG & 1.384 & $0.955-2.006$ & 0.086 & 0.0 & 0.932 \\
\hline Codominance GA vs. GG & 0.008 & $0.004-0.017$ & 0.000 & 83.6 & 0.000 \\
\hline Complete overdominance & 0.827 & $0.761-0.899$ & 0.000 & 0.0 & 0.434 \\
\hline \multicolumn{6}{|l|}{ Caucasian } \\
\hline Allele contrast & 1.121 & $1.060-1.186$ & 0.000 & 0.0 & 0.964 \\
\hline Dominant & 1.127 & $1.047-1.213$ & 0.001 & 0.0 & 0.919 \\
\hline Recessive & 1.203 & $1.067-1.357$ & 0.003 & 0.0 & 0.987 \\
\hline Codominance AA vs. GG & 1.284 & $1.131-1.456$ & 0.000 & 0.0 & 0.893 \\
\hline Codominance GA vs. GG & 0.279 & $0.132-0.587$ & 0.001 & 98.0 & 0.000 \\
\hline Complete overdominance & 0.959 & $0.891-1.033$ & 0.272 & 0.0 & 0.457 \\
\hline
\end{tabular}

Notes: $I^{2}$ represents the variation in OR attributable to heterogeneity. $P_{\mathrm{h}}$ represents the $P$-value of the Q-test for heterogeneity Abbreviations: $C l$ confidence interval; $O R$ odds ratio

\section{Sensitivity analysis and publication bias}

Delete each study item by item, and then calculate the significance of the new meta-analysis results consisting of the remaining studies [36]. We did not observe statistically significant differences, indicating that the current results are reliable and stable and have not been affected by any separate studies. (Table 5). The symmetry of the funnel plots can reflect the publication bias (Figs. 2, 3, 4, 5, 6, 7, 8 and 9). Egger's test quantifies the publication bias analysis. Due to the lack of studies on rs4765905, the efficacy of the
Egger's test was limited, and the symmetry of the funnel plot could not be detected. We did not find publication bias in the rs2007044 ( $G$ vs. $A ; t=-0.43, P=0.743$ ) or rs4765905 (A vs. G; $t=0.86, P=0.407$ ) allele model. For rs1006737, there were no publication biases in the dominant (GA + AA vs. GG: $P=0.613, t=0.52$ ), recessive (TT vs. GG + GT: $P=0.507, t=-0.68$ ), codominant (AA vs. GG: $P=0.713, t=-0.38)$ and complete overdominance (GG + TT vs. GT: $P=0.762, t=-0.31)$ models. However, there was a publication bias for the rs1006737 polymorphism

Table 5 Results of the sensitivity analysis for the CACNA1C rs1006737 polymorphism

\begin{tabular}{|c|c|c|c|c|c|}
\hline \multicolumn{2}{|l|}{ Excluded } & \multirow[t]{2}{*}{ OR } & \multirow[t]{2}{*}{$95 \% \mathrm{Cl}$} & \multirow{2}{*}{$\begin{array}{l}\boldsymbol{P} \text { - } \\
\text { value }\end{array}$} & \multirow[t]{2}{*}{$P_{\mathrm{h}}$} \\
\hline Study & Sample & & & & \\
\hline Lubeiro & Caucasian & 1.1506206 & $1.0998443-1.2037411$ & 0.000 & 0.815 \\
\hline Fatima & Caucasian & 1.1546086 & $1.1033095-1.2082929$ & 0.000 & 0.878 \\
\hline Mallas & Mixed & 1.1497633 & $1.0989355-1.202942$ & 0.000 & 0.826 \\
\hline Porcelli & Asian & 1.1485037 & $1.0978361-1.2015097$ & 0.000 & 0.903 \\
\hline Ivorra & Caucasian & 1.166579 & $1.1047648-1.2318518$ & 0.000 & 0.866 \\
\hline $\mathrm{He}$ & Asian & 1.1393697 & $1.0879437-1.1932266$ & 0.000 & 0.981 \\
\hline Guan & Asian & 1.1452636 & $1.0925845-1.2004827$ & 0.000 & 0.847 \\
\hline Galaktionova & Caucasian & 1.1542471 & $1.1029066-1.2079774$ & 0.000 & 0.863 \\
\hline Zheng & Asian & 1.1498204 & $1.094684-1.2077338$ & 0.000 & 0.815 \\
\hline Hori & Asian & 1.1508508 & $1.0996418-1.2044445$ & 0.000 & 0.814 \\
\hline Zhang & Asian & 1.1517017 & $1.1007836-1.204975$ & 0.000 & 0.821 \\
\hline Nyegaard & Caucasian & 1.154137 & $1.0994588-1.2115344$ & 0.000 & 0.821 \\
\hline Bigos & Caucasian & 1.1496404 & $1.0980188-1.2036888$ & 0.000 & 0.818 \\
\hline Green & Caucasian & 1.151419 & $1.0981367-1.2072866$ & 0.000 & 0.814 \\
\hline
\end{tabular}

Notes: $P_{\mathrm{h}}$ represents the $P$-value of the Q-test for heterogeneity Abbreviations: $\mathrm{Cl}$ confidence interval; $O R$ odds ratio 


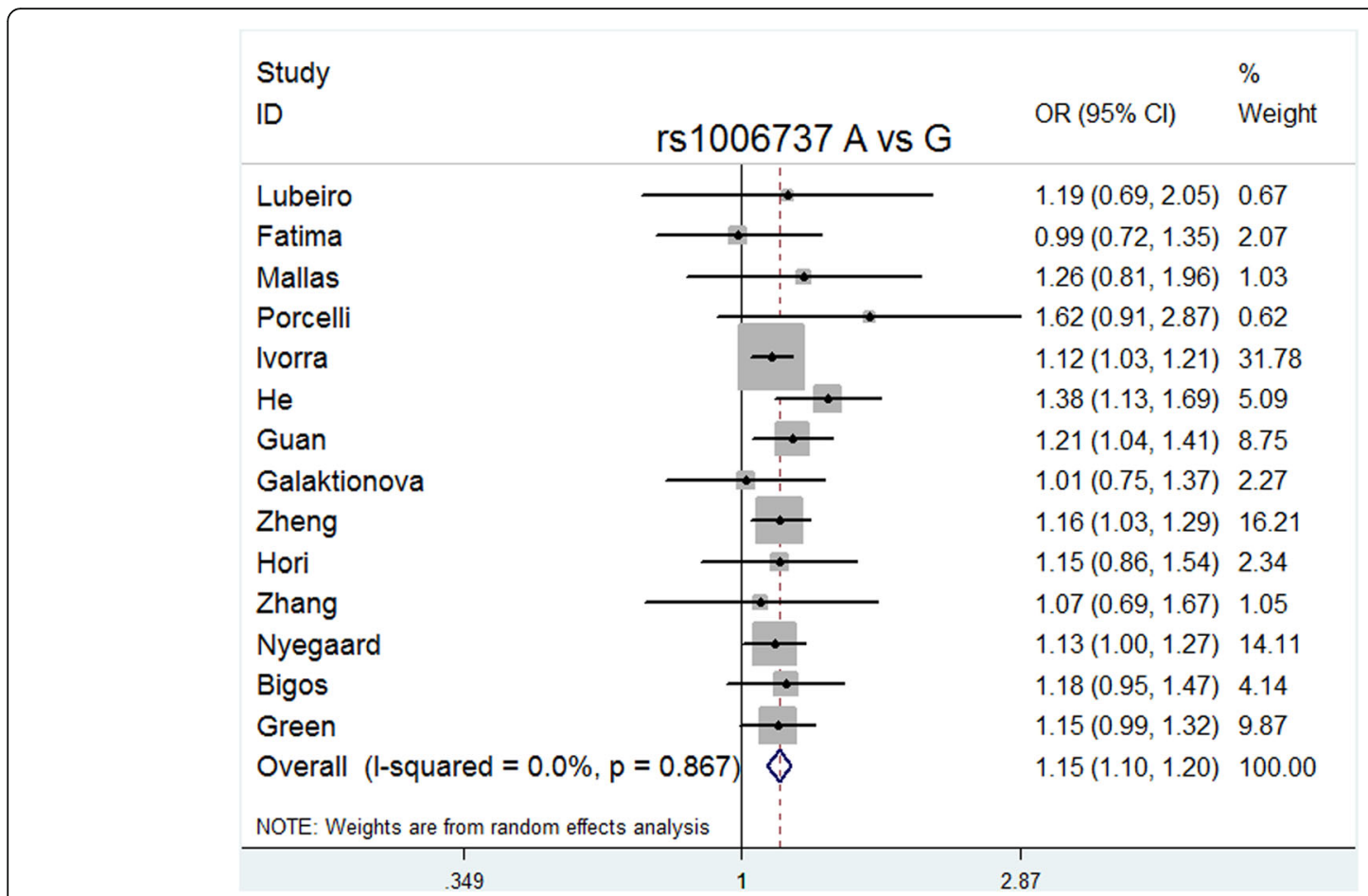

Fig. 2 Forest plot of the allele contrast model (A vs. G) for rs1006737. Significant differences between rs1006737 and the risk of schizophrenia were observed with the allele contrast model ( $T$ vs. G) $(O R=1.151,95 \% \mathrm{Cl}=1.100-1.204$, $P$ heterogeneity $=0.867, P=0.000)$

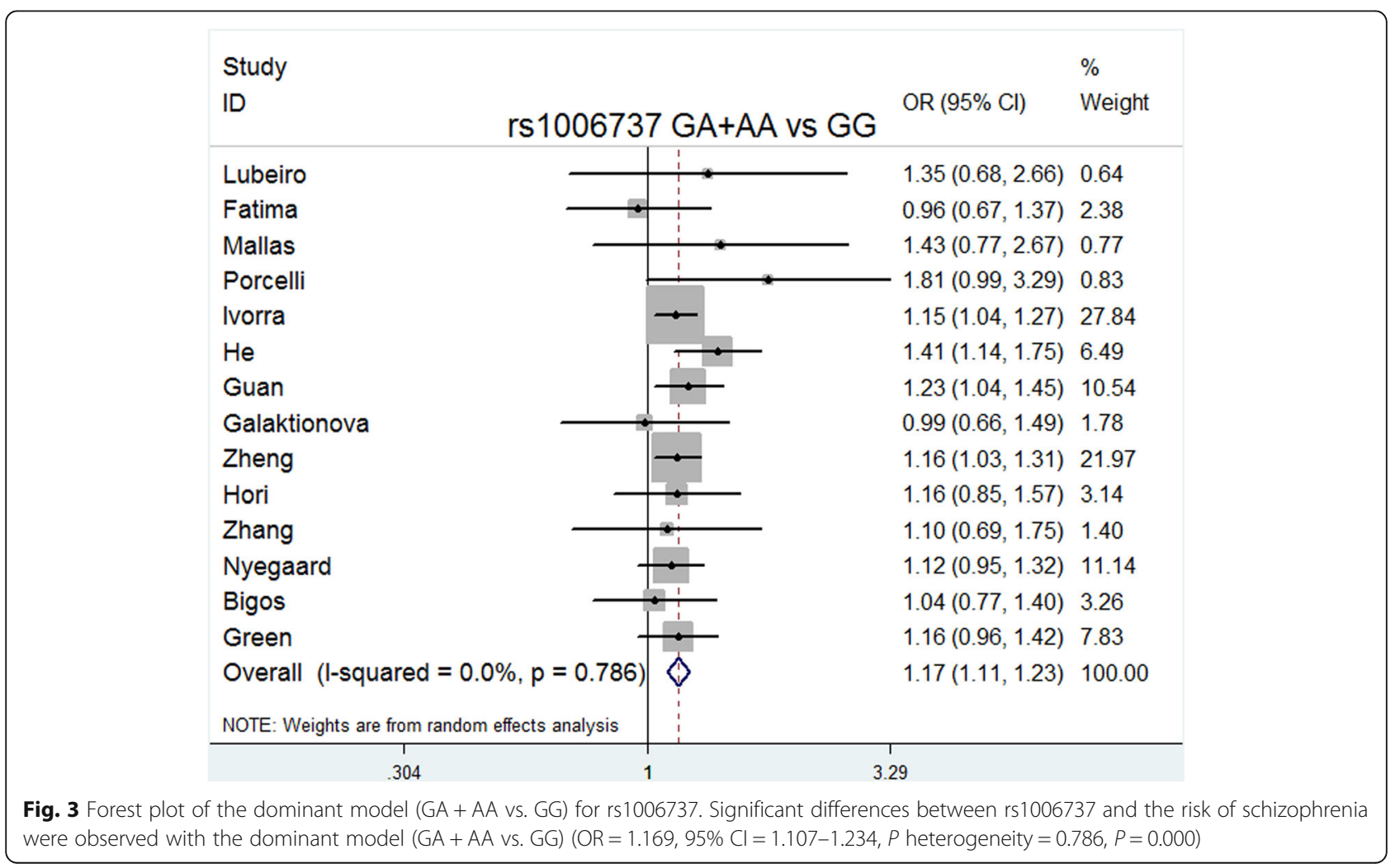




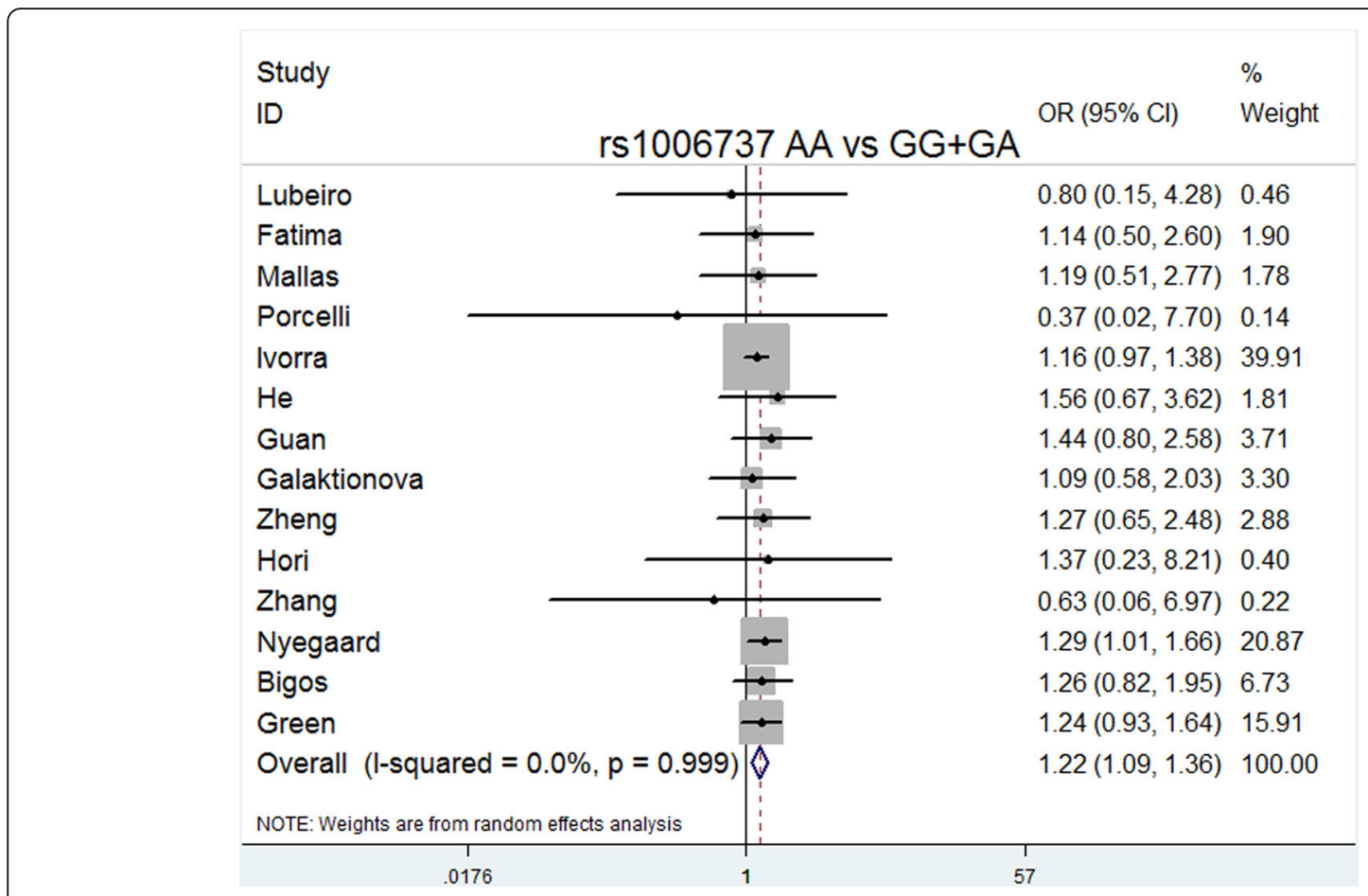

Fig. 4 Forest plot of the recessive model (AA vs. GG + GA) for rs 1006737. Significant differences between rs 1006737 and the risk of schizophrenia were observed with the recessive model (AA vs. GG $+\mathrm{GA})(\mathrm{OR}=1.215,95 \% \mathrm{Cl}=1.085-1.360$, $P$ heterogeneity $=0.999, P=0.001)$

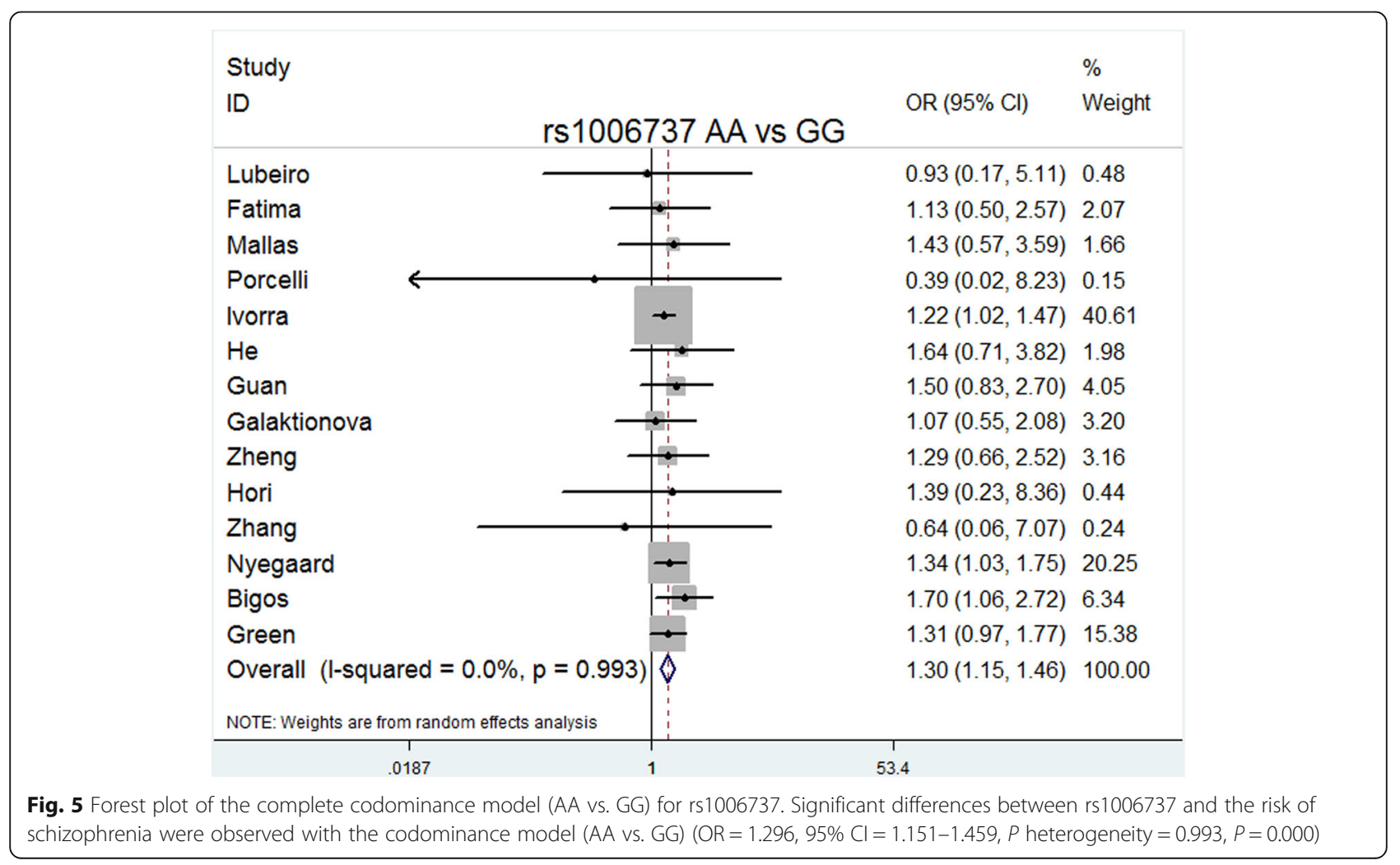




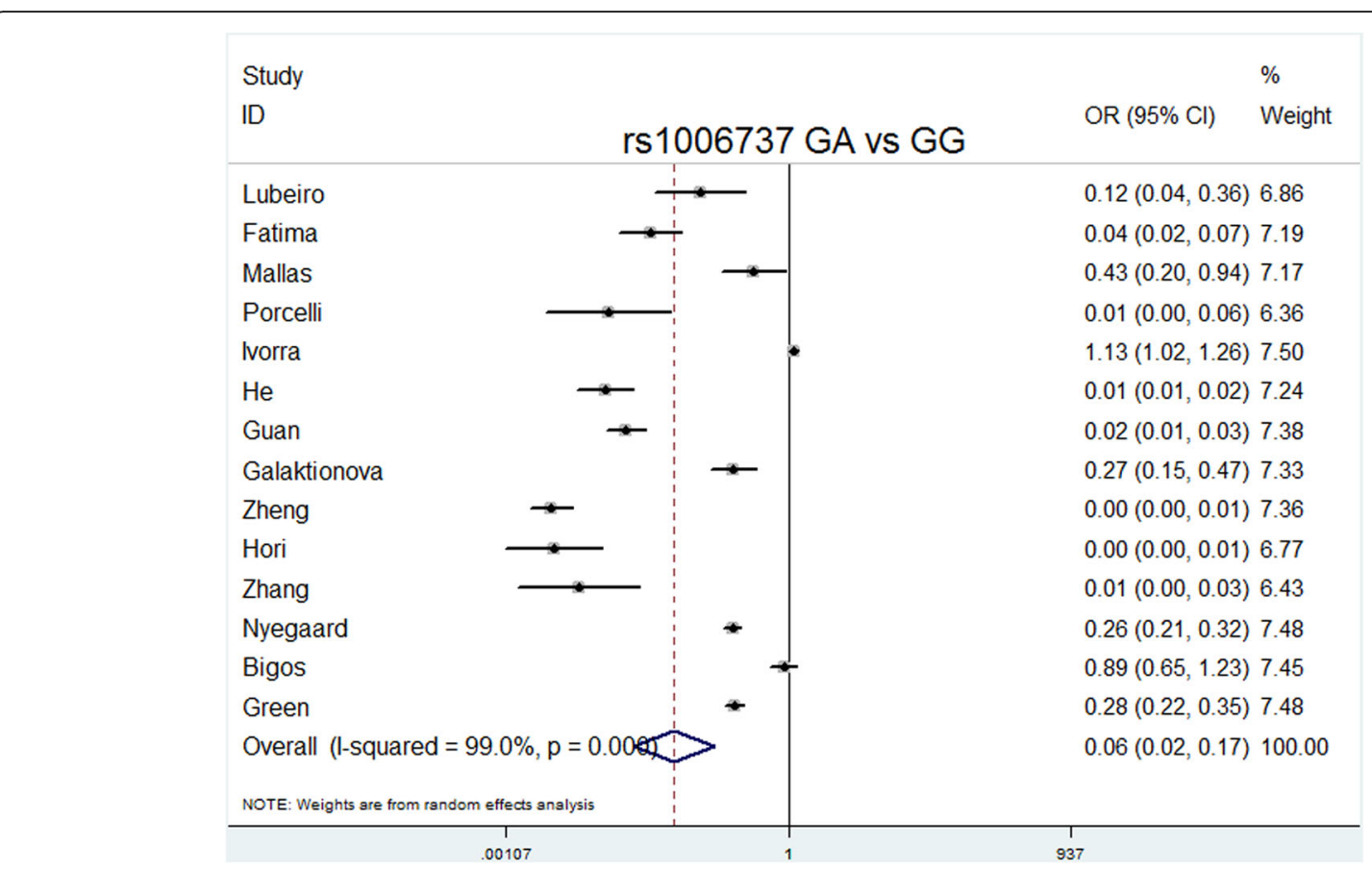

Fig. 6 Forest plot of the codominance model (GA vs. GG) for rs1006737. Significant differences between rs1006737 and the risk of schizophrenia were observed with the codominance model (GA vs. GG) $(\mathrm{OR}=0.064,95 \% \mathrm{Cl}=0.024-0.169$, $P$ heterogeneity $=0.000, P=0.000)$

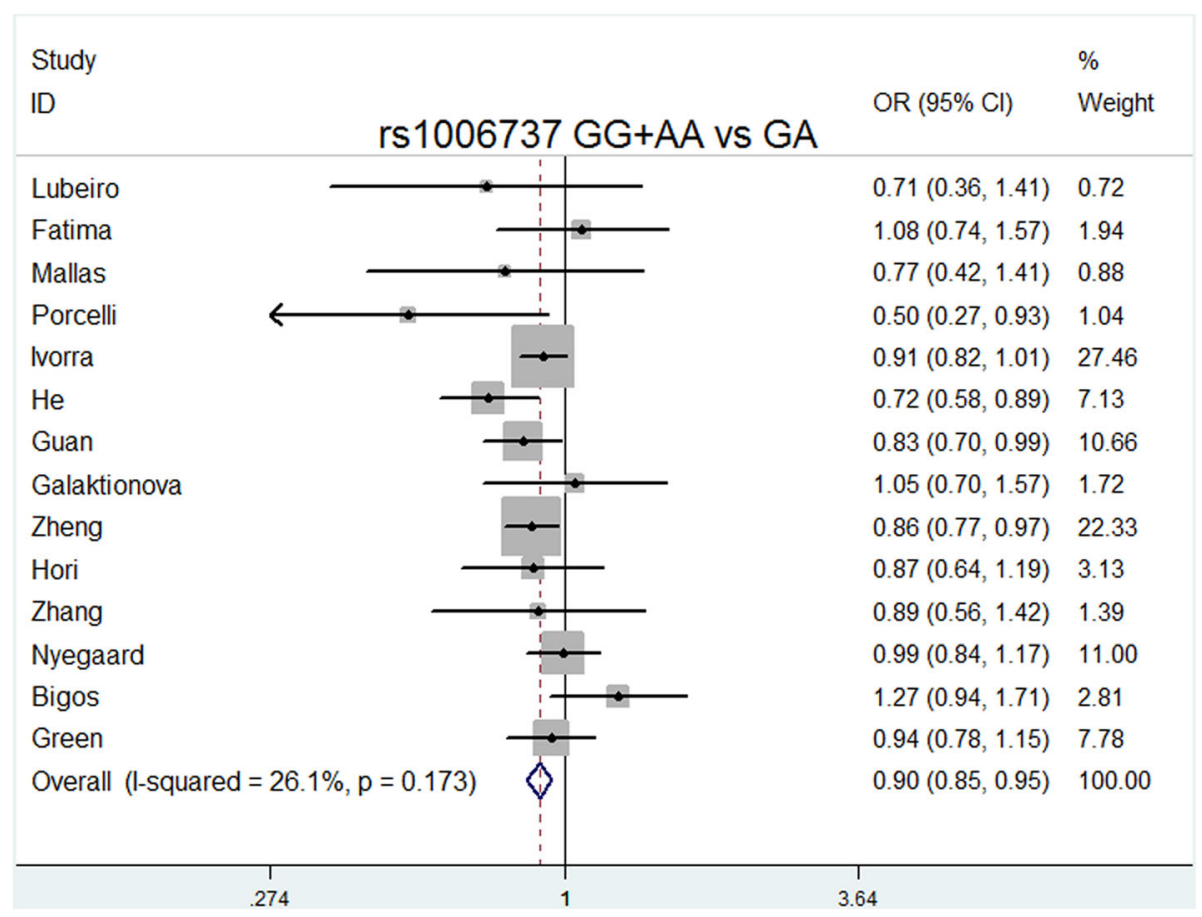

Fig. 7 Forest plot of the complete overdominance model (GG + AA vs. GA) for rs1006737. Significant differences between rs1006737 and the risk of schizophrenia were observed with the complete overdominance model (GG + AA vs. GA) $(\mathrm{OR}=0.897,95 \% \mathrm{Cl}=0.849-0.948$, $P$ heterogeneity $=0.173, P=0.000)$ 


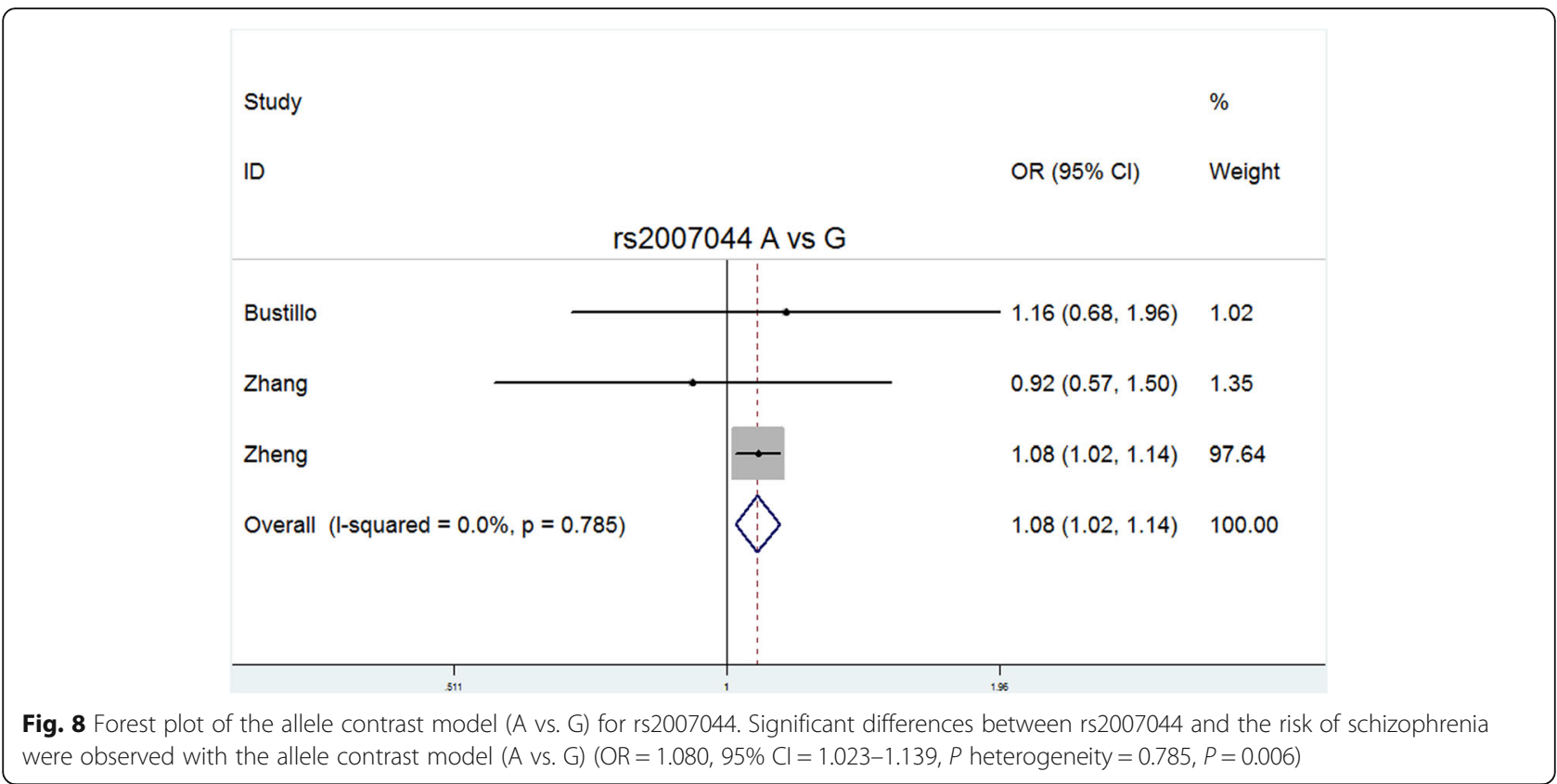

with the codominance model (AA vs. GG; $t=-3.88, P=$ 0.002).

\section{Discussion}

CACNA1C is associated with bipolar disorder [37], autism spectrum disorder [38], major depression [15], and other central nervous system (CNS) disorders [39]. However, the association between the CACNA1C gene and schizophrenia has not been determined. It is also unclear whether the CACNA1C gene has the same effect on schizophrenia in both Asians and Europeans. Therefore, we conducted a comprehensive meta-analysis on the association between the CACNA1C rs1006737, rs2007044, and rs4765905 polymorphisms and schizophrenia. In the overall analysis, rs1006737 was associated with the risk of schizophrenia in all five genetic models, and rs2007044 and rs4765905 were also related to schizophrenia in the allele model, implying that the $C A C N A 1 C$ gene may influence the risk of schizophrenia. This view is consistent with the results of previous meta-analyses [13, 14, 16, 35, 40, 41].

When we conducted a race-based subgroup analysis of rs1006737, we found that the effects of rs1006737 on

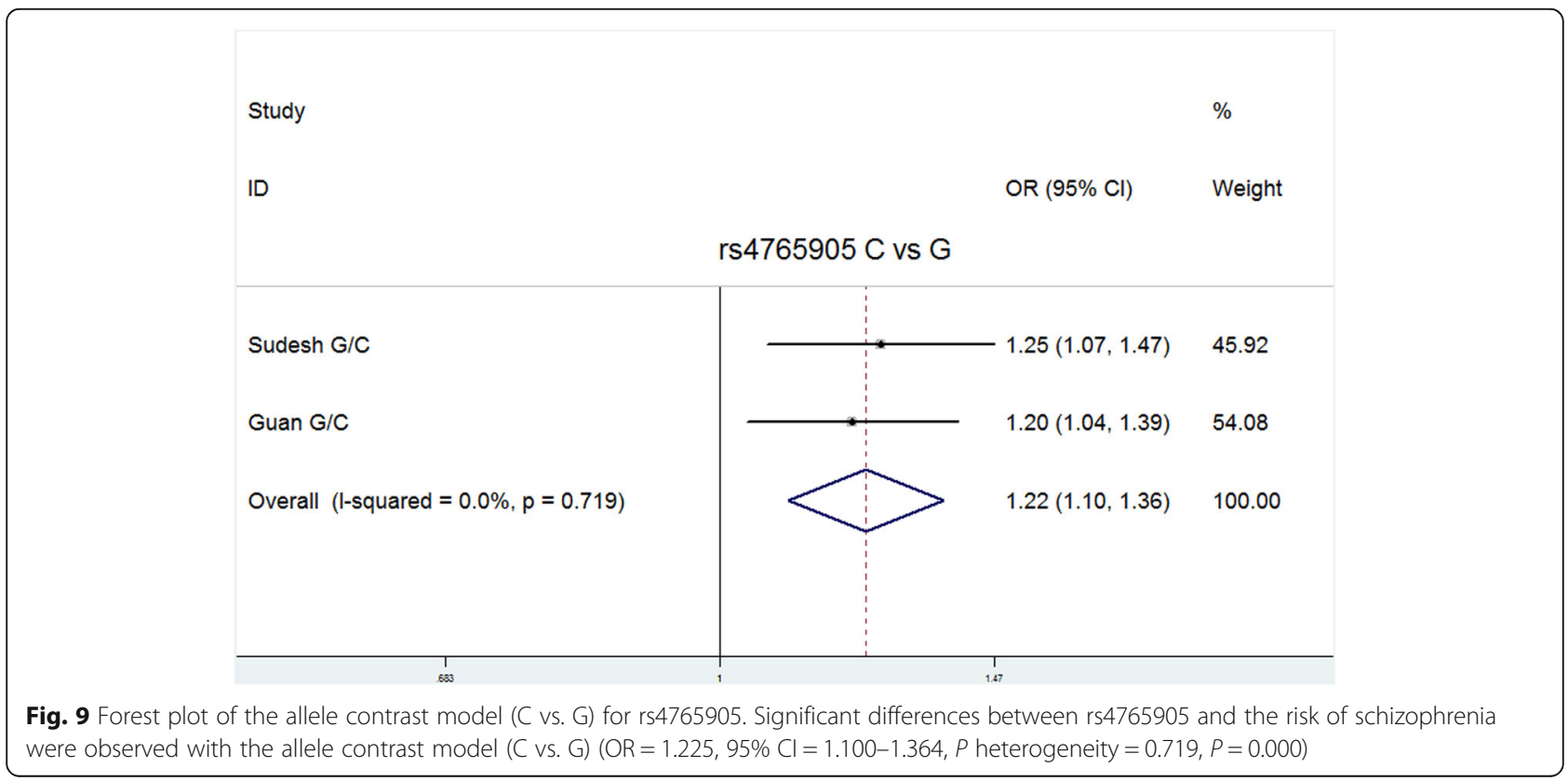


schizophrenia in the Asians and Europeans had both similarities and differences. According to the results obtained with the allele (A vs. G) and dominant (GA + AA vs. GG) models, the effect of rs1006737 on the risk of schizophrenia in the Europeans and Asians was consistent (i.e., allele $\mathrm{A}$ and genotype GA + AA were protective factors against the development of schizophrenia). However, analysis by the recessive (AA vs. GG+ GA) and codominant (AA vs. GG) models showed that the genotype GG + GA was only a risk factor for schizophrenia in the European sample. In contrast, according to the complete overdominance model (GG + AA vs. GA), the GA genotype of rs1006737 only reduced the risk of schizophrenia in the Asian sample. These data suggest that the effect of rs1006737 on schizophrenia is ancestrally diverse.

The current study has two limitations. Due to significant heterogeneity $\left(\mathrm{I}^{2}=99.0 \%\right)$ and publication bias (Egger's test $P=0.002$ ), the codominant model (GA vs. GG) was not reliable and, therefore, was not a valid gene model for evaluating the rs1006737 polymorphism. In addition, there were few studies on the association between rs2007044 or rs4765905 and schizophrenia. Thus, additional high-quality studies are needed to support our analysis.

This meta-analysis study advanced our understanding of the relationship between $C A C N A 1 C$ polymorphisms and schizophrenia compared to previous literature. First, the current study included more comprehensive studies. A recent meta-analysis of the CACNA1C gene and schizophrenia [40] contained nine studies on the association between rs1006737 and schizophrenia. In comparison, the current study included 14 studies on the association between this polymorphism and schizophrenia, including eight articles $[11,13,15,18,23,25,26,28]$ shared with [40] along with six additional studies [8, 20-22, 24, 27]. Second, compared to most of the meta-analysis on CACNA1C and schizophrenia, the current study not only included studies on rs1006737 and schizophrenia but also studies on the association between two other CACNA1C polymorphisms (rs2007044 and rs4765905) and schizophrenia. Although the study of Xiao et al. [41] also included these three polymorphisms, it only included samples from Asian samples. Because the current study included samples from both Asians and Europeans, it used a richer source of samples for the analysis. Finally, the current study focused on comparing the impact of rs1006737 on schizophrenia in Asian and European samples. Based on this analysis, the influence model of rs1006737 on schizophrenia in Asian and European samples identified both similarities and differences between the two samples.

\section{Conclusions}

The CACNA1C rs1006737, rs2007044, and rs4765905 gene polymorphisms were associated with the susceptibility to schizophrenia. However, the influence model for rs1006737 on schizophrenia in Asians and Europeans demonstrated both similarities and differences between the two ancestors.

\section{Abbreviations}

GWAS: Genome-wide association study; SNP: Single nucleotide

polymorphism; PGC: Psychiatric Genomics Consortium; OR: Odds ratio; 95\% Cl: 95\% confidence interval

\section{Acknowledgements}

We would like to thank Professor Mei Ding for her guidance and review of the data analysis.

\section{Authors' contributions}

YPL participated in the study design and drafted the manuscript. XW and XX performed the statistical analysis. BJW and JY contributed to the revision of the final manuscript. All authors have read and approved the manuscript.

\section{Funding}

The present research was not funded by any funding agency in the public, commercial, or not-for-profit sectors.

\section{Availability of data and materials}

All data generated or analyzed during this study are included in this published article.

Ethics approval and consent to participate

Not applicable.

\section{Consent for publication}

Not applicable.

\section{Competing interests}

The authors declare that they have no competing interests.

Received: 18 February 2020 Accepted: 2 July 2020

Published online: 08 August 2020

\section{References}

1. Mowry BJ, Nancarrow DJ. Molecular genetics of schizophrenia. Clin Exp Pharmacol Physiol. 2001:28:66-9.

2. Kendler KS. Overview: a current perspective on twin studies of schizophrenia. Am J Psychiatry. 1983:140:1413-25.

3. Kety SS. Schizophrenic illness in the families of schizophrenic adoptees: findings from the Danish national sample. Schizophr Bull. 1988;14:217-22.

4. Soeiro-de-Souza MG, Bio DS, Dias W, Vieta E, Machado-Vieira R, Moreno RA. The CACNA1C risk allele selectively impacts on executive function in bipolar type I disorder. Acta Psychiatr Scand. 2013;128:362-9.

5. Barad M. Later developments: molecular keys to age-related memory impairment. Alzheimer Dis Assoc Disord. 2003;17:168-76.

6. Leitch B, Szostek A, Lin R, Shevtsova O. Subcellular distribution of L-type calcium channel subtypes in rat hippocampal neurons. Neuroscience. 2009; 164:641-57

7. Cross-Disorder Group of the Psychiatric Genomics C. Identification of risk loci with shared effects on five major psychiatric disorders: a genome-wide analysis. Lancet. 2013:381:1371-9.

8. Ivorra JL, Rivero O, Costas J, Iniesta R, Arrojo M, Ramos-Rios R, et al. Replication of previous genome-wide association studies of psychiatric diseases in a large schizophrenia case-control sample from Spain. Schizophr Res. 2014;159:107-13.

9. Wolf C, Mohr H, Schneider-Axmann T, Reif A, Wobrock T, Scherk H, et al. CACNA1C genotype explains interindividual differences in amygdala volume among patients with schizophrenia. Eur Arch Psychiatry Clin Neurosci. 2014;264:93-102.

10. Gallagher M, Chiba AA. The amygdala and emotion. Curr Opin Neurobiol. 1996;6:221-7.

11. Fatima A, Faroog M, Abdullah U, Tariq M, Mustafa T, Iqbal M, et al. Genomewide supported risk variants in MIR137, CACNA1C, CSMD1, DRD2, and 
GRM3 contribute to schizophrenia susceptibility in Pakistani population. Psychiatry Investig. 2017;14:687-92.

12. Eckart N, Song Q, Yang R, Wang R, Zhu H, McCallion AS, et al. Functional characterization of schizophrenia-associated variation in CACNA1C. PLoS One. 2016;1 :e0157086.

13. Zheng F, Zhang Y, Xie W, Li W, Jin C, Mi W, et al. Further evidence for genetic association of CACNA1C and schizophrenia: new risk loci in a Han Chinese population and a meta-analysis. Schizophr Res. 2014;152:105-10.

14. Jiang H, Qiao F, Li Z, Zhang Y, Cheng Y, Xu X, et al. Evaluating the association between CACNA1C rs1006737 and schizophrenia risk: a metaanalysis. Asia Pac Psychiatry. 2015;7:260-7.

15. He K, An Z, Wang Q, Li T, Li Z, Chen J, et al. CACNA1C, schizophrenia and major depressive disorder in the Han Chinese population. $\mathrm{Br} J$ Psychiatry. 2014;204:36-9.

16. Nie F, Wang X, Zhao P, Yang H, Zhu W, Zhao Y, et al. Genetic analysis of SNPs in CACNA1C and ANK3 gene with schizophrenia: a comprehensive meta-analysis. Am J Med Genet B Neuropsychiatr Genet. 2015;168:637-48.

17. Takahashi S, Glatt SJ, Uchiyama M, Faraone SV, Tsuang MT. Meta-analysis of data from the psychiatric genomics consortium and additional samples supports association of CACNA1C with risk for schizophrenia. Schizophr Res. 2015;168:429-33.

18. Hori H, Yamamoto N, Fujii T, Teraishi T, Sasayama D, Matsuo J, et al. Effects of the CACNA1C risk allele on neurocognition in patients with schizophrenia and healthy individuals. Sci Rep. 2012;2:634

19. Liu YP, Meng JH, Wu X, Xu FL, Xia X, Zhang XC, et al. Rs 1625579 polymorphism in the MIR137 gene is associated with the risk of schizophrenia: updated meta-analysis. Neurosci Lett. 2019;713:134535.

20. Lubeiro A, Fatjo-Vilas M, Guardiola M, Almodovar C, Gomez-Pilar J, CeaCanas $\mathrm{B}$, et al. Analysis of $\mathrm{KCNH} 2$ and $\mathrm{CACNA1C}$ schizophrenia risk genes on EEG functional network modulation during an auditory odd-ball task. Eur Arch Psychiatry Clin Neurosci. 2020;270:433-42.

21. Mallas E, Carletti F, Chaddock CA, Shergill S, Woolley J, Picchioni MM, et al. The impact of CACNA1C gene, and its epistasis with ZNF804A, on white matter microstructure in health, schizophrenia and bipolar disorder(1). Genes Brain Behav. 2017;16:479-88.

22. Porcelli S, Lee SJ, Han C, Patkar AA, Serretti A, Pae CU. CACNA1C gene and schizophrenia: a case-control and pharmacogenetic study. Psychiatr Genet. 2015;25:163-7.

23. Guan F, Zhang B, Yan T, Li L, Liu F, Li T, et al. MIR137 gene and target gene CACNA1C of miR-137 contribute to schizophrenia susceptibility in Han Chinese. Schizophr Res. 2014;152:97-104.

24. Galaktionova D, Gareeva AE, Khusnutdinova EK, Nasedkina TV. The association of polymorphisms in SLC18A1, TPH1 and RELN genes with risk of paranoid schizophrenia. Mol Biol (Mosk). 2014;48:629-39.

25. Zhang $Q$, Shen $Q, X u$ Z, Chen M, Cheng L, Zhai J, et al. The effects of CACNA1C gene polymorphism on spatial working memory in both healthy controls and patients with schizophrenia or bipolar disorder. Neuropsychopharmacology. 2012;37:677-84

26. Nyegaard M, Demontis D, Foldager L, Hedemand A, Flint TJ, Sorensen KM et al. CACNA1C (rs1006737) is associated with schizophrenia. Mol Psychiatry. 2010;15:119-21.

27. Bigos KL, Mattay VS, Callicott JH, Straub RE, Vakkalanka R, Kolachana B, et al. Genetic variation in CACNA1C affects brain circuitries related to mental illness. Arch Gen Psychiatry. 2010;67:939-45.

28. Green EK, Grozeva D, Jones I, Jones L, Kirov G, Caesar S, et al. The bipolar disorder risk allele at CACNA1C also confers risk of recurrent major depression and of schizophrenia. Mol Psychiatry. 2010;15:1016-22.

29. Bustillo JR, Patel V, Jones T, Jung R, Payaknait N, Qualls C, et al. RiskConferring Glutamatergic Genes and Brain Glutamate Plus Glutamine in Schizophrenia. Front Psychiatry. 2017:8:79

30. Zhang Z, Wang Y, Zhang Q, Zhao W, Chen X, Zhai J, et al. The effects of CACNA1C gene polymorphism on prefrontal cortex in both schizophrenia patients and healthy controls. Schizophr Res. 2019;204:193-200.

31. Sudesh R, Thalamuthu A, John S, Thara R, Mowry B, Munirajan AK Replication of GWAS identified miR-137 and its target gene polymorphisms in Schizophrenia of South Indian population and meta-analysis with Psychiatric Genomics Consortium. Schizophr Res. 2018;199:189-94.

32. Egger M, Davey Smith G, Schneider M, Minder C. Bias in meta-analysis detected by a simple, graphical test. BMJ. 1997;315:629-34.

33. Wu R, Li B. A multiplicative-epistatic model for analyzing interspecific differences in outcrossing species. Biometrics. 1999;55:355-65.
34. Higgins JP, Thompson SG, Deeks JJ, Altman DG. Measuring inconsistency in meta-analyses. BMJ. 2003:327:557-60

35. Yang X, Wang G, Wang Y, Yue X. Association of metabotropic glutamate receptor 3 gene polymorphisms with schizophrenia risk: evidence from a meta-analysis. Neuropsychiatr Dis Treat. 2015;11:823-33.

36. Li HF, Yan LP, Wang K, Li XT, Liu HX, Tan W. Association between ADAM33 polymorphisms and asthma risk: a systematic review and meta-analysis. Respir Res. 2019;20:38.

37. Khalid M, Driessen TM, Lee JS, Tejwani L, Rasool A, Saqlain M, et al. Association of CACNA1C with bipolar disorder among the Pakistani population. Gene. 2018;664:119-26.

38. Li J, Zhao L, You Y, Lu T, Jia M, Yu H, et al. Schizophrenia related variants in CACNA1C also confer risk of autism. PLoS One. 2015;10:e0133247.

39. Moon AL, Haan N, Wilkinson LS, Thomas KL, Hall J. CACNA1C: association with psychiatric disorders, behavior, and neurogenesis. Schizophr Bull. 2018; 44:958-65.

40. Zhu D, Yin J, Liang C, Luo X, Lv D, Dai Z, et al. CACNA1C (rs1006737) may be a susceptibility gene for schizophrenia: An updated meta-analysis. Brain Behav. 2019;9:e01292.

41. Xiao X, Luo XJ, Chang H, Liu Z, Li M. Evaluation of European schizophrenia GWAS loci in Asian populations via comprehensive meta-analyses. Mol Neurobiol. 2017:54:4071-80.

\section{Publisher's Note}

Springer Nature remains neutral with regard to jurisdictional claims in published maps and institutional affiliations.
Ready to submit your research? Choose BMC and benefit from:

- fast, convenient online submission

- thorough peer review by experienced researchers in your field

- rapid publication on acceptance

- support for research data, including large and complex data types

- gold Open Access which fosters wider collaboration and increased citations

- maximum visibility for your research: over $100 \mathrm{M}$ website views per year

At $\mathrm{BMC}$, research is always in progress.

Learn more biomedcentral.com/submissions 